\title{
Paradigmas del Turismo Sostenible en la Parroquia de Lloa
}

\author{
Paradigms of Sustainable Tourism in the Lloa Parish
}

Mg. Ismari Gómez

Universidad Tecnológica Israel

igomez@uisrael.edu.ec

Mg. Francisco Vinueza

Universidad Tecnológica Israel

Mg. Salomé Villafuerte

Universidad Tenológica Israel

Ing. Sara Obando

Compañía externa

Fecha de recepción: 10/04/2016

Fecha de aceptación: 12/05/2016

\section{Resumen}

El desarrollo económico en las parroquias rurales en la Provincia de Pichincha siempre ha estado encaminado a las actividades primarias como: son la ganadería, agricultura, pesca, etc. Sin embargo, por sus características geomorfológicas tienen potencial turístico, como ejemplo tenemos el caso de la parroquia rural de Lloa en donde se han encontrado potenciales importantes de atractivos turísticos tanto naturales como culturales. 
El presente estudio tiene como objetivo definir el paradigma turístico en la parroquia de Lloa, realizando un análisis de la oferta y la demanda turística existente.

Desde la demanda se realiza una encuesta cualitativa y cuantitativa para determinar el perfil del turista que llega a la parroquia, además de obtener cuales son los atractivos turísticos más valorados en la parroquia y desde la oferta se analizan los tres pilares fundamentales que son el hospedaje, la alimentación, transporte y los atractivos turísticos que se pueden encontrar en Lloa.

Palabras clave: Turismo Sostenible, parroquias rurales, oferta, demanda

\begin{abstract}
Economic development in rural parishes in the Province of Pichincha has always been directed to primary activities such as livestock, agriculture, fishing, etc. However, because of its geomorphological characteristics have tourist potential, as an example we have the case of the rural parish of Lloa where important potentials of natural and cultural tourist attractions have been found. The present study aims to define the tourism paradigm in the parish of Lloa, performing an analysis of the existing tourism supply and demand.

From the demand a qualitative and quantitative survey is carried out to determine the profile of the tourist who arrives in the parish, as well as obtaining the most valuable tourist attractions in the parish and from the offer, the three fundamental pillars are the lodging, The food, transport and tourist attractions that can be found in Lloa.
\end{abstract}

Keywords: Sustainable Tourism, rural parishes, offer, demand 


\section{Introducción}

El presente estudio se desarrolla en la Parroquia de Lloa, Provincia de Pichincha, constituye la más extensa del Distrito Metropolitano de Quito, pues cuenta con un territorio de $54.725 \mathrm{~km} 2$, el cual posee una altura que varía entre los 1.800 y 4.675 metros de altura sobre el nivel del mar, condición geográfica que permite el desarrollo de una gran variedad de pisos climáticos y paisajes, además de poseer gran parte de este territorio bosque primario, esto hace que tenga algunos recursos turísticos que podrían ser aprovechados por la población local para mejorar su economía mediante el Turismo Sostenible.

Lloa significa Planicie en lo Alto, es una mezcla del vocablo Cara y Colorado, que fueron las poblaciones que más incidencia tuvieron en el sector que hoy conocemos como Lloa.

En la Parroquia de Lloa existen diez asentamientos humanos conocidos, de los cuales cuatro son legalmente constituidos, estos asentamientos están a lo largo de las vías principales de la parroquia, a excepción del barrio La Victoria (que se encuentra en el Km. 35 de la vía que va desde la parroquia urbana de Chillogallo hacia arriba pasando por San Juan De Chillogallo hasta la Victoria), y la comunidad de Chiriboga (que se encuentra sobre la vía antigua a Santo Domingo partiendo desde Chillogallo).

Dentro de los asentamientos podemos mencionar a: la cabecera parroquial, Concepción de Monjas, Cooperativa de Vivienda 29 de Mayo, Chilcapamba, La Tablera, Palmira, San José del Cinto, San Luis, Urauco, La Victoria, por último podemos indicar que actualmente se determina con exactitud la ubicación de la comunidad de Chiriboga, que está en la antigua vía que va desde Quito a Santo Domingo de los Colorados y casualmente en el límite cantonal pero pertenece definitivamente a la parroquia de Lloa.

Se ha considerado como asentamiento humano a la Cooperativa de Vivienda, Cooperativas Agrícolas, Asociaciones Agrícolas por su ubicación, su cantidad de socios y su espacio que ocupan territorialmente.

La parte nororiental de Lloa que comprende el centro poblado y zonas aledañas se caracteriza por tener un clima frío húmedo, con una temperatura media anual de $12^{\circ} \mathrm{C}$, en la parte alta del volcán Pichincha la temperatura desciende a cuatro grados. El resto de la parroquia que tiene que ver con las zonas que descienden hacia la Costa posee un clima cálido con una temperatura que va de los dieciocho a los veinte grados centígrados. (Sierra, R. 1999.) 
Según esta investigación en el diagnóstico se demuestra principalmente que la economía de la parroquia está basado en actividades primarias como: son la ganadería, agricultura, pesca, minería además de microempresas y demostraciones de emprendimientos turísticos.

Lloa a pesar de poseer muchos recursos naturales de gran belleza e infraestructura turística carece de la afluencia de turistas debido a la falta de un modelo de gestión, por lo cual no han generado un ingreso económico esperado por la comunidad.

De acuerdo a sus recursos naturales y culturales, Lloa puede desarrollar diferentes modelos de productos turísticos como: el turismo rural, turismo de aventura, turismo cultural, turismo comunitario, turismo termal.

Con esta investigación se pretende llegar a establecer que la comunidad de Lloa puede cambiar de una economía primaria a economías con más valor agregado, como la terciaria, con un desarrollo del turismo como eje principal para mejorar las condiciones sociales y ambientales de su población.

\section{Objetivo general}

Definir el paradigma turístico en la parroquia de Lloa para mejorar las condiciones de vida de la población local.

\section{Objetivos específicos}

- Evaluar los aspectos económicos, sociales y ambientales de la parroquia de Lloa.

- Identificar los atractivos turísticos que actualmente existen en la parroquia de Lloa y su estado.

\section{Método}

\section{Histórico lógico}

Para la investigación se tomó como referencia el método histórico lógico, el cual permite recopilar información a través de la historia por medio de libros, revistas y páginas de internet. Así se obtuvo la información sobre la caracterización ambiental, socioeconómica, demográfica y turística de la parroquia de Lloa.

\section{Analítico}

Mediante este método se logró explicar y entender de mejor manera las diferentes necesidades que enfrenta el royecto, teniendo un diagnóstico más claro para dar una solución concreta a través de un modelo de gestión. 


\section{Inductivo}

Está basado en la recopilación y procesamiento de datos ya sean de fuentes primarias o secundarias; de esa manera se obtendrá la información verídica que permita resolver los problemas actuales.

\section{Estadísticos}

Tabulación e interpretación de resultados en lo que corresponde a la encuesta aplicada a los habitantes para analizar qué tanto se conocen y se han potenciado los atractivos turísticos de la parroquia Lloa.

\section{Técnicas}

La técnica que se va a utilizar para el estudio y factibilidad de este proyecto es la encuesta, la cual se tomó de muestra la Población Económicamente Activa (PEA) que según el último censo realizado en el año 2010 por el INEC son 848 personas, mediante el cálculo estadístico se obtuvo una muestra de 264 personas a las cuales se les aplicó la encuesta, teniendo en consideración el objetivo general de la investigación.

\section{Determinación del universo y muestra}

Para calcular el tamaño de la muestra se utilizó la siguiente fórmula:

$$
n=\frac{N \sigma^{2} Z^{2}}{(N-1) e^{2}+\sigma^{2} Z^{2}}
$$

Donde:

- $\mathrm{n}=$ el tamaño de la muestra.

- $\mathrm{N}=$ tamaño de la población.

- $\sigma=$ Desviación estándar de la población que, generalmente cuando no se tiene su valor, suele utilizarse un valor constante de 0,5 .

- $\mathrm{Z}=$ Valor obtenido mediante niveles de confianza. Es un valor constante que, si no se tiene su valor, se lo toma en relación al 95\% de confianza equivale a 1,96 (como más usual) o en relación al 99\% de confianza equivale 2,58, valor que queda a criterio del investigador.

- e = Límite aceptable de error de la muestra que, generalmente cuando no se tiene su valor, suele utilizarse un valor que varía entre el $1 \%(0,01)$ y $9 \%(0,09)$, valor que queda a criterio del encuestador (Interaprendizaje de Estadística Básica, 2011). 
Datos de la Población Económicamente Activa de Lloa

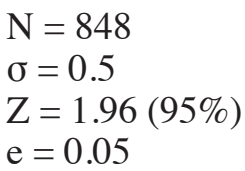

Cálculo de la muestra:

$$
\mathrm{n}=\frac{848 * 0.5^{2} 1.96^{2}}{(848-1) 0.01^{2}+0.5^{2} 1.96^{2}}=264.6
$$

La población económicamente activa es aquella población que se encuentra comprendida entre los 15 a los 65 años edad, y que tienen la potencialidad de vincularse a las actividades productivas, ya sea que tengan empleo o trabajo remunerado o están a la espera de tenerlo.

Para calcular la PEA de la parroquia Lloa se tomó en cuenta las políticas del INEC para su cálculo así para el 2001 la población económicamente activa fue de 736 personas. Para el 2010 la PEA es de 848 habitantes.

Gráfica 1. Población Económicamente Activa PEA 2001-2010

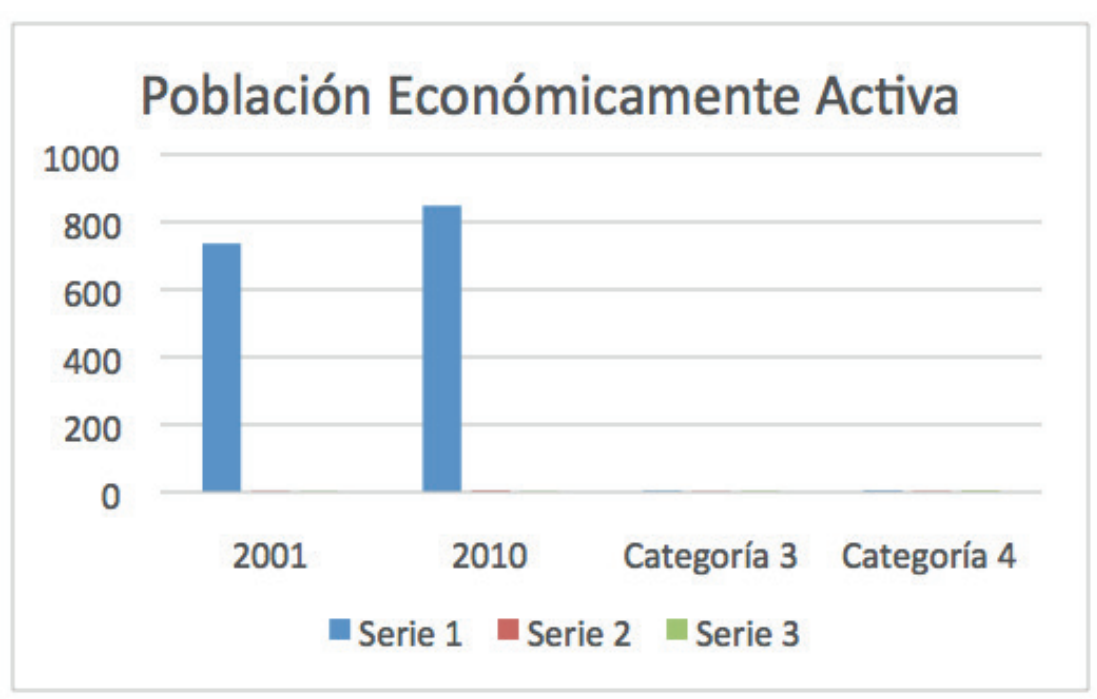

Fuente: INEC 2001 
Se puede determinar que en los últimos años la parroquia de Lloa ha tenido un crecimiento considerable en lo que se refiere a su economía.

\section{Análisis e interpretación de resultados}

Posteriormente, se presenta los resultados obtenidos de la encuesta que se realizó.

Tabla - Resultado de Edad

\begin{tabular}{|l|r|r|r|}
\hline \multicolumn{1}{|c|}{ RANGO } & & \multicolumn{1}{|c|}{ NÚMERO } & PORCENTAJE \\
\hline $18-25$ años & 66 & 66 & $25 \%$ \\
\hline $26-33$ años & 115 & 115 & $44 \%$ \\
\hline de 34 años en adelante & 83 & 83 & $31 \%$ \\
\hline & TOTAL & 264 & $100 \%$ \\
\hline
\end{tabular}

Tabla.- Resultado de Género

\begin{tabular}{|l|r|r|}
\hline & NÚMERO & PORCENTAJE \\
\hline Masculino & 64 & $24 \%$ \\
\hline Femenino & 200 & $76 \%$ \\
\hline Total & 264 & $100 \%$ \\
\hline
\end{tabular}

Tabla.- Resultado de Instrucción

\begin{tabular}{|c|c|c|c|}
\hline & & TOTAL & PORCENTAJE \\
\hline Primaria & 184 & 184 & $70 \%$ \\
\hline Secundaria & 61 & 61 & $23 \%$ \\
\hline Superior & 19 & 19 & $7 \%$ \\
\hline & & 264 & $100 \%$ \\
\hline
\end{tabular}


Tabla.- Resultado de Nacionalidad

\begin{tabular}{|l|r|r|}
\hline & TOTAL & \multicolumn{1}{|c|}{ PORCENTAJE } \\
\hline Ecuatoriano & 264 & $100 \%$ \\
\hline Extranjero & 0 & $0 \%$ \\
\hline Total & 264 & $100 \%$ \\
\hline
\end{tabular}

Tabla.- Resultado de Ocupación

\begin{tabular}{|l|r|r|r|}
\hline \multicolumn{2}{|c|}{} & TOTAL & OCUPACIÓN \\
\hline Profesionales & 45 & 45 & $17 \%$ \\
\hline Estudiantes & 15 & 15 & $6 \%$ \\
\hline Comerciantes & 166 & 166 & $63 \%$ \\
\hline Agricultores & 38 & 38 & $14 \%$ \\
\hline \multicolumn{2}{r|}{ TOTAL } & 264 & $100 \%$ \\
\hline
\end{tabular}

PREGUNTA 1: ¿Conoce o ha recibido alguna guía turística de la parroquia de Lloa? - Sí No

Tabla.- Resultados pregunta 1

\begin{tabular}{|l|r|r|r|}
\hline \multicolumn{2}{|c|}{} & TOTAL & PORCENTAJE \\
\hline Sí & 76 & 76 & $29 \%$ \\
\hline No & 188 & 188 & $71 \%$ \\
\hline \multicolumn{2}{r|}{ TOTAL } & 264 & $100 \%$ \\
\hline
\end{tabular}

Análisis: Mediante los resultados obtenidos se identifica que un $71 \%$ de los habitantes no ha recibido alguna guía turística de la parroquia, mientras que un $29 \%$ indica que sí ha recibido, por lo tanto la implementación de un impreso que muestre los atractivos turísticos sería de ayuda para la promoción turística de la zona.

PREGUNTA 2: ¿Califique del 1 al 5 que tan beneficioso sería la implementación de una guía turística permitirá incentivar el turismo y orientar a los visitantes para que se conduzcan a los diferentes lugares de recreación? Siendo 5 excelente, 4 muy bueno, 3 bueno, 2 regular y 1 malo. 
Tabla.- Resultados pregunta 2

\begin{tabular}{|l|r|r|r|}
\hline \multicolumn{2}{|c|}{} & TOTAL & PORCENTAJE \\
\hline Excelente & 113 & 113 & $43 \%$ \\
\hline Muy bueno & 38 & 38 & $15 \%$ \\
\hline Bueno & 45 & 45 & $17 \%$ \\
\hline Regular & 30 & 30 & 11 \\
\hline Malo & 38 & 38 & $14 \%$ \\
\hline \multicolumn{2}{|r|}{ TOTAL } & 264 & $100 \%$ \\
\hline
\end{tabular}

Análisis: Basándose en las respuestas de los encuestados, el 43\% responde que la implementación de la guía de atractivos turísticos permitirá incentivar el turismo en la parroquia; ya que existe poca difusión y conocimiento de los lugares naturales y culturales que tiene este lugar por esa razón es necesario que Lloa cuente con este medio de comunicación, un 14\% respondió que esto no permitirá incentivar el turismo.

PREGUNTA 3: ¿Ha trabajado en actividades turísticas con alguna remuneración o por cuenta propia?

Tabla.- Resultados pregunta 3

\begin{tabular}{|l|r|r|r|}
\hline \multicolumn{2}{|c|}{} & \multicolumn{1}{r|}{ TOTAL } & PORCENTAJE \\
\hline Sí & 16 & 16 & $6 \%$ \\
\hline No & 248 & 248 & $94 \%$ \\
\hline & TOTAL & 264 & $100 \%$ \\
\hline
\end{tabular}

Análisis: Según los resultados obtenidos el 94\% no ha prestado servicios turísticos y el $6 \%$ en algún momento se ha involucrado en actividades turísticas.

PREGUNTA 4: ¿Piensa Ud. que con esta guía mejorará la actividad económica de la parroquia? Sí - No

Tabla.- Resultados pregunta 4

\begin{tabular}{|c|c|c|c|}
\hline \multicolumn{3}{|r|}{ TOTAL } & \multirow{2}{*}{$\begin{array}{r}\text { PORCENTAJE } \\
72 \%\end{array}$} \\
\hline Sí & 189 & 189 & \\
\hline No & 75 & 75 & $28 \%$ \\
\hline & TOTAL & 264 & $100 \%$ \\
\hline
\end{tabular}


Análisis: El 72\% de los encuestados respondió positivamente, ya que por medio de la guía de atractivos turísticos se podría implementar plazas de trabajo mejorando la economía de los pobladores, mientras que un $28 \%$ respondió negativamente indicando que no sería de ayuda para el incremento económico de los pobladores.

PREGUNTA 5: ¿Cree usted que la incorporación de la guía turística permitirá el incremento de fuentes de empleo? Sí - No

Tabla.- Resultado pregunta 5

\begin{tabular}{|l|r|r|r|}
\hline & & TOTAL & PORCENTAJE \\
\hline Sí & 189 & 189 & $72 \%$ \\
\hline No & 75 & 75 & $28 \%$ \\
\hline & TOTAL & 264 & $100 \%$ \\
\hline
\end{tabular}

Análisis: El 72\% de los encuestados considera que la implementación de la guía permitirá un incremento de fuentes de empleo, ya que al momento de satisfacer las necesidades del turista se podría abrir más lugares de alojamiento, alimentación y actividad turística, mientras que un $28 \%$ considera que no ayudará.

PREGUNTA 6: Seleccione lo que crea conveniente debe ofrecer la guía turística

Tabla.- Resultado pregunta 6

\begin{tabular}{|c|c|c|c|}
\hline \multicolumn{3}{|r|}{ TOTAL } & \multirow{2}{*}{$\begin{array}{r}\text { PORCENTAJE } \\
35 \%\end{array}$} \\
\hline Imágenes & 91 & 91 & \\
\hline Reseña histórica & 23 & 23 & $9 \%$ \\
\hline Alojamiento y alimentación & 38 & 38 & $14 \%$ \\
\hline Lugares turísticos & 45 & 45 & $17 \%$ \\
\hline Cultura & 30 & 30 & $11 \%$ \\
\hline Fiestas & 8 & 8 & $3 \%$ \\
\hline Ruta turística & 22 & 22 & $8 \%$ \\
\hline Plan de comunicación & 7 & 7 & $3 \%$ \\
\hline & TOTAL & 264 & $100 \%$ \\
\hline
\end{tabular}


Análisis: En una relación del $100 \%$ para cada indicador, se establece que la guía turística debe contener un $35 \%$ de imágenes, un $17 \%$ sobre lugares turísticos, $14 \%$ sobre hoteles y restaurantes, un $11 \%$ sobre cultura, un $9 \%$ reseña histórica, $8 \%$ sobre rutas turísticas y un $3 \%$ información sobre fiestas y plan de comunicación.

PREGUNTA 7: Califique del 1 al 5 si se debe crear un departamento de información turística que sea la encargada de proveer estas guías a los visitantes y turistas, Siendo 5 excelente, 4 muy bueno, 3 bueno, 2 regular y 1 malo.

Tabla.- Resultados pregunta 7

\begin{tabular}{|l|r|r|r|}
\hline \multicolumn{2}{|c|}{} & \multicolumn{1}{|c|}{ TOTAL } & PORCENTAJE \\
\hline Excelente & 151 & 151 & $57 \%$ \\
\hline Muy bueno & 30 & 30 & $11 \%$ \\
\hline Bueno & 68 & 68 & $26 \%$ \\
\hline Regular & 15 & 15 & $6 \%$ \\
\hline Malo & 0 & 0 & $0 \%$ \\
\hline \multicolumn{2}{|c|}{ TOTAL } & 264 & $100 \%$ \\
\hline
\end{tabular}

Análisis: Un 57\% de los encuestados respondió positivamente en la creación de un departamento que brinde información turística adecuada la cual esté disponible todos los días donde se pueda impartir la guía a todos los visitantes, mientras que un $6 \%$ calificó como innecesario este departamento.

PREGUNTA 8: ¿Qué lugares turísticos considera usted que puedan tener mayor desarrollo turístico en la parroquia?

Tabla.- Resultados pregunta 8

\begin{tabular}{|c|c|c|c|}
\hline \multicolumn{3}{|r|}{ TOTAL } & PORCENTAJE \\
\hline Volcán & 75 & 75 & $28 \%$ \\
\hline Cascadas & 76 & 76 & $29 \%$ \\
\hline Aguas termales & 60 & 60 & $23 \%$ \\
\hline Iglesias & 38 & 38 & $14 \%$ \\
\hline
\end{tabular}




\begin{tabular}{|r|r|r|r|}
\hline Bosques & 15 & 15 & $6 \%$ \\
\hline & TOTAL & 264 & $100 \%$ \\
\hline
\end{tabular}

Análisis: El 29\% considera que se ha promocionado con mayor dedicación el Volcán Guagua Pichincha, el 28\% las cascadas, el 23\% el Complejo de aguas termales, el 14\% las iglesias y un $6 \%$ los bosques existentes. Por lo tanto, no existe una mayor difusión sobre otros lugares turísticos del cantón.

PREGUNTA 9: ¿El municipio ha cumplido con la obra pública vial para que exista un fácil acceso a todos los lugares turísticos? Sí - No

Tabla.- Resultados pregunta 9

\begin{tabular}{|l|r|r|r|}
\hline & \multicolumn{2}{|c|}{ TOTAL } & PORCENTAJE \\
\hline Sí & 113 & 113 & $43 \%$ \\
\hline No & 151 & 151 & $57 \%$ \\
\hline & TOTAL & 264 & $100 \%$ \\
\hline
\end{tabular}

Análisis: Para el 57\% de los encuestados el Municipio no ha cumplido con la obra pública vial para que exista un fácil acceso a todos los lugares turísticos de la parroquia de Lloa, en cambio el 30 \% sí lo considera así.

PREGUNTA 10: ¿Los pobladores de Lloa reciben capacitación para brindar información a los visitantes?

Tabla.- Resultados pregunta 10

\begin{tabular}{|l|r|r|r|}
\hline & \multicolumn{2}{|c|}{ TOTAL } & PORCENTAJE \\
\hline Sí & 80 & 80 & $30 \%$ \\
\hline No & 184 & 184 & $70 \%$ \\
\hline & TOTAL & 264 & $100 \%$ \\
\hline
\end{tabular}

Análisis: Según los resultados el $70 \%$ de los habitantes de la parroquia de Lloa no han recibido capacitación por parte del GAD para brindar información a los turistas, a diferencia de un 30\% que sí ha recibido capacitación. 


\section{Análisis de la Encuesta}

- Se determina que la guía turística es necesaria dados los resultados obtenidos en la aplicación de las encuestas a la PEA que considera en un $43 \%$ que sí cree se debe implementar de una guía turística que permitirá incentivar el turismo y orientar a los visitantes para que se conduzcan a los diferentes lugares de recreación.

- Además, un $97 \%$ establece que la guía debe llevar imágenes e información correspondiente a elementos estructurales: imágenes, reseña histórica, información en inglés, mapas de ubicación, información de hoteles y restaurantes y lugares turísticos.

- De igual manera un $72 \%$ la población está de acuerdo en que la guía mejorará la actividad económica de la parroquia.

\section{Metas o productos propuestos según su tipo}

\section{Atractivos turísticos}

Mediante una tabla se detallarán los atractivos turísticos según la categoría, tipo, subtipo y jerarquización que tiene la parroquia de Lloa. Para el inventario de los atractivos turísticos se empleó la metodología sugerida por el Ministerio de Turismo del Ecuador al 2016.

Tabla.- Sitios Naturales

\begin{tabular}{|c|c|c|c|c|c|c|}
\hline Atractivo & Categoría & Tipo & Subtipo & Jerarquía & Público & Privado \\
\hline Volcán Guagua Pichincha & Sitio natural & Montaña & Volcán & II & $\mathrm{x}$ & \\
\hline $\begin{array}{c}\text { Bosque protector } \\
\text { Mindo - Nambillo }\end{array}$ & $\begin{array}{c}\text { Sitios } \\
\text { naturales }\end{array}$ & Bosques & $\begin{array}{c}\text { Nublado } \\
\text { occidental }\end{array}$ & $\mathrm{I}$ & $\mathrm{x}$ & \\
\hline Termas de Palmira & Sitio natural & $\begin{array}{c}\text { Aguas } \\
\text { subterráneas }\end{array}$ & $\begin{array}{c}\text { Aguas } \\
\text { termales }\end{array}$ & $\mathrm{I}$ & $\mathrm{x}$ & \\
\hline Mirador El Cinto & Sitio natural & Montañas & Colinas & $\mathrm{I}$ & $\mathrm{x}$ & \\
\hline Cascada de los Corazones & Sitio natural & Río & Cascada & $\mathrm{I}$ & $\mathrm{x}$ & \\
\hline Cascada de las 7 Caras & Sitio natural & Río & Cascada & $\mathrm{I}$ & $\mathrm{x}$ & \\
\hline Cascadas Manto de Novia & Sitio natural & Río & Cascada & $\mathrm{I}$ & $\mathrm{x}$ & \\
\hline Cascada de Palmira & Sitio natural & Río & Cascada & $\mathrm{I}$ & $\mathrm{x}$ & \\
\hline Cascada Playa Escondida & Sitio natural & Río & Cascada & $\mathrm{I}$ & $\mathrm{x}$ & \\
\hline
\end{tabular}




\section{Manifestaciones culturales}

Lloa al igual que la mayoría de parroquias rurales de Quito, guarda en sus edificios, tradiciones e historia, un gran acervo cultural factible de ser considerado como atractivo turístico; por este motivo se citan a continuación las más importante manifestaciones culturales.

Tabla.- Sitios Culturales

\begin{tabular}{|c|c|c|c|c|c|c|}
\hline Atractivo & Categoría & Tipo & Subtipo & Jerarquía & Público & Privado \\
\hline Santuario El Cinto & $\begin{array}{c}\text { Manifestaciones } \\
\text { culturales }\end{array}$ & Históricas & Religiosas & II & $\mathrm{x}$ & \\
\hline Centro poblado de Lloa & $\begin{array}{c}\text { Manifestaciones } \\
\text { culturales }\end{array}$ & Históricas & $\begin{array}{c}\text { Zonas } \\
\text { históricas }\end{array}$ & I & $\mathrm{x}$ & \\
\hline Centro cultural Alegría Fonseca & $\begin{array}{c}\text { Manifestaciones } \\
\text { culturales }\end{array}$ & Históricas & Museo & I & $\mathrm{x}$ & \\
\hline $\begin{array}{c}\text { Festividades de la } \\
\text { Vírgen del Volcán }\end{array}$ & $\begin{array}{c}\text { Manifestaciones } \\
\text { culturales }\end{array}$ & Históricas & Religiosas & I & $\mathrm{x}$ & \\
\hline Iglesia de Lloa & $\begin{array}{c}\text { Manifestaciones } \\
\text { culturales }\end{array}$ & Folklore & Religiosas & I & $\mathrm{x}$ & \\
\hline
\end{tabular}

\section{Alojamiento}

En cuanto a los establecimientos hoteleros Lloa cuenta con hosterías, posadas y cabañas que brindan los servicios necesarios para la pernoctación de los visitantes. Entre ellas las más destacadas son la Hostería La Antigua que cuenta con una capacidad de 25 pax, con restaurante donde ofrecen diferentes platos típicos de la zona y se puede realizar actividades como fogatas, ordeño, paseos a caballo, camping, entre otras. Esta hostería es la más visitada por los turistas ya que se encuentra a $5 \mathrm{~km}$ del parque central de Lloa.

También se puede encontrar la hostal Casa y Campo con una capacidad para 20 personas en habitaciones simples, dobles y familiares con baño privado, agua caliente y TV.

Otro establecimiento hotelero es Molino Adventure Park que ofrece diferentes actividades recreativas como caminatas, cuadrones, agroturismo, pesca deportiva y adicionalmente hospedaje y camping. 
Tabla.- Alojamiento en Lloa

\begin{tabular}{|c|l|c|c|}
\hline Tipo & \multicolumn{1}{|c|}{ Nombre } & Plazas & Categoría \\
\hline \multirow{2}{*}{ Hosterías y posadas } & $\bullet$ Hostería Las plamas & 20 & SC \\
& $\bullet$ Hostería La Antigüa & 25 & SC \\
\hline \multirow{2}{*}{ Cabañas } & $\bullet$ Sierra Verde & 15 & SC \\
& $\bullet$ Casa y campo & 20 & \\
\hline Campings & El Molino Adventure Park & Total plazas: 100 & \\
\hline
\end{tabular}

\section{Alimentación}

Con respecto a la infraestructura de los diferentes restaurantes ubicados en la zona podemos encontrar la comida típica en el centro del poblado como el Rincón de la Abuelita María, Virgen del Cinto y Rincón del Buen Sabor, son los tres restaurantes que brindan la oportunidad al turista de deleitarse de la gastronomía típica de Lloa.

Los tres se ubican alrededor de la plaza central y brindan su atención de viernes a domingo. Su menú ofrece: caldos de gallina, yaguarlocro, fritada, trucha frita, morocho, empanadas de viento, humitas, quimbolitos, choclos, habas, quesos, chicha, etc.

Todos estos sitios no cuentan con categorización y las instalaciones que poseen son rústicas pero con un servicio de calidad.

Tabla.- Restaurantes y comedores en Lloa

\begin{tabular}{|c|l|c|c|}
\hline Tipo & Nombre & Aforo & Categoría \\
\hline \multirow{3}{*}{ Restaurantes } & - La antigua & 50 & SC \\
& • La Vígen del Cinto & 50 & SC \\
& - Mi Abuelita María & 40 & SC \\
\hline \multirow{3}{*}{ Comedores típicos } & - Picantería La Parada & 20 & SC \\
& - Ricón del Buen Sabor & 50 & SC \\
\hline & & Total: 210 & \\
\hline
\end{tabular}




\section{Establecimientos Recreacionales}

En la zona existen lugares de recreación donde se puede practicar actividades como pesca deportiva, deportes de aventura y agroturismo. A continuación se mencionan los establecimientos que brindan este servicio.

Tabla.- Establecimientos Recreacionales en Lloa

\begin{tabular}{|c|c|c|l|}
\hline Tipo & Nombre & Categoría & \multicolumn{1}{c|}{ Actividades } \\
\hline \multirow{2}{*}{ Rancho } & Don Manucho & SC & $\begin{array}{l}\text { La piscícola Don Manucho ofrece pesca de- } \\
\text { portes de aventura como tarabita, boyas y cabo } \\
\text { comando, también existe ojo de aguas termales, } \\
\text { pesca deportiva y venta de truchas. }\end{array}$ \\
\cline { 2 - 4 } & La Delicia & SC & $\begin{array}{l}\text { Ofrece las siguientes actividades: caminatas, ob- } \\
\text { servación de flora y fauna nativa, cascadas, pes- } \\
\text { ca deportiva. }\end{array}$ \\
\hline Granja & Agroecológica San José & SC & $\begin{array}{l}\text { Las actividades que realiza es el ordeño, realiza- } \\
\text { ción de quesos y yogurt. }\end{array}$ \\
\hline \multirow{2}{*}{ Recintos } & Cebauco & SC & $\begin{array}{l}\text { Los servicios que brinda son cabalgatas con un } \\
\text { pony (30 minutos), una piscina de agua termal } \\
\text { observar la flora y fauna nativa de la zona. }\end{array}$ \\
\hline
\end{tabular}

\section{Transporte}

Actualmente existe la Cooperativa de Transportes Lloa, la cooperativa tiene 10 unidades, que salen de sus oficinas en la calle Angamarca y Mariscal Sucre, llegan a la entrada de la Mena 2 y tiene como destino el centro poblado de Lloa, en la calle Pichincha y Antonio Piedra. Opéra de lunes a domingo de 06h00 a 19 h00 desde Lloa a la Mena. 


\section{Conclusiones}

A través del estudio de la parroquia de Lloa se pudieron detallar los aspectos económicos, sociales y ambientales, obteniendo así datos reales que ayudaron a realizar el diagnóstico de la parroquia.

Mediante el recorrido y levantamiento de los atractivos turísticos se pudo identificar la información relevante y el estado de conservación de cada uno de los lugares estudiados.

Se realizó una guía de los atractivos turísticos de la parroquia de Lloa para brindar información clara y específica de los sitios que se pueden visitar en esta zona. 


\section{Recomendaciones}

Se debería implementar un departamento en las oficinas de la Junta Parroquial que brinde información sobre los atractivos turísticos que tiene la parroquia de Lloa.

Es necesario colocar señalética que indique por donde se puede llegar a los atractivos turísticos.

Se recomienda que los pobladores reciban capacitación sobre la importancia del turismo en su comunidad para que de esa manera exista una mejor promoción y difusión de los sitios a visitar.

Se debería poner más énfasis en la infraestructura vial ya que los caminos son de tierra y eso demora la llegada a los atractivos turísticos aún más cuando el día está lluvioso.

Se recomienda que la Junta Parroquial de Lloa incorpore a un plan de promoción turística la guía elaborada. 


\section{Bibliografía}

Baroja G. (2012) “Plan de desarrollo i ordenamiento territorial de Lloa 2012-2025.”

Censo INEC, 2010

Consejo Provincial de Pichincha: Plan de desarrollo participativo 2002 -2012.

Dirube J. (2007):“Un Modelo de Gestión por Competencias”.

Eliseo R. (2009). : Técnicas de investigación de campo

Fundación CODESFA. (2013): "PROGRAMA RUTAS: La apuesta por un turismo inclusivo en Latinoamérica.”

Limón R. (2007): "La Ciencia y el Método Científico"

Magliz R. (2009, 12): "Ensayo Método Inductivo Y Deductivo.”

Meci S. (2011):“Modelo de gestión de Procesos”

Páez Luis Alberto Von Lippke, Etnografía de la parroquia de Lloa, 1 Edición, Imprenta Municipal, Quito Ecuador, Enero 2010, p.107

“Plan Nacional del Buen vivir 2013 - 2017” capturado de: http://www.buenvivir.gob.ec/

Puig A. (2006): “Los Nuevos Negocios Turísticos. Buenos aires”. Valleta Ediciones S.R.L

Ruiz V. (2012) "Plan de desarrollo turístico comunitario para la parroquia de Lloa, D.M. de Quito, provincia de Pichincha." capturado de: http://www.dspace.uce.edu.ec/handle/25000/1108

Santafé V: (2008): "Plan de desarrollo estratégico de turismo para la Parroquia de Lloa, cantón Quito." capturado de: http://repositorio.ute.edu.ec/bitstream/123456789/1477/1/34628_1.pdf

Senplades. (2011):"Guía de contenidos y procesos para la formulación de Planes de Desarrollo y Ordenamiento Territorial de provincias, cantones y parroquias" 
